\section{Future of US space programme}

SIR-Your leading article. "Who wants the US space station?" ( Nature 325, 745: 1987), raises important questions which must be answered quickly by planners and participants in the US space programme. Three years of study of space station plans by responsible representatives of the United States and the international space science community have. in fact. identified important scientific uses for a large, manned science facility in low Earth orbit. These include support for major astronomical, solar-terrestrial and Earth observing projects as well as initiation of serio $\ldots$ s study of materials science and technology and life science in microgravity. However, the extent to which the current NASA (National Aeronautics and Space Administration) plans for space science and the space station are adequate and can be justified in the face of recent developments spawned by the Challenger accident is open to debate.

My personal concern arises from the following. First, for the foreseeable future. the space shuttle must be regarded as a fragile, irregular transport vehicle which will be hostage to a variety of practical considerations, including substantial oversubscription by its users. Even its flight frequency will remain in doubt for some extended period. Nevertheless, the current space station plans rely exclusively upon the availability of this vehicle for all aspects of station construction and supply. With an estimated flight rate of about 12 per year, the current space station plan requires the equivalent of 2.5 years of dedicated shuttle flights. Is this a responsible plan for such an important programme? Is this the only possible alternative?

Second, as a consequence of the Challenger accident, serious disruptions have arisen in the national space science programme. NASA's science plans before the accident included the equivalent of 76 shuttle payloads (on the shuttle and other unmanned vehicles) between fiscal year 1986 and fiscal year 1995. As a consequence, many proposed and funded experiments have been put aside, creating a crisis in space science that has yet to be addressed in any meaningful way. Unfortunately, as discussed below, the space station plans have evolved independently of this situation.

Third, estimates of the acquisition and operating costs of the currently planned space station have climbed because of new costing procedures, reduced space shuttle flight capabilities and new and improved

Letters submitted for Correspondence should be typed, double-spaced, on one side of the paper only. knowledge of space station system requirements. This has introduced a substantial delay in the projected start of the construction project and lengthened its duration. With the present plan, a moderate level of science work with the space station seems improbable until late 1995 or early 1996. This delay in the availability of the space station, taken in concert with the decline in science flights associated with the space shuttle, presages a decade of reduced opportunity for space science investigations, even taking into account the flight of major facilities such as the Hubble Space Telescope, Galileo, the Gamma Ray Observatory, the Upper Atmosphere Research Satellite and others.

Finally, one of the great difficulties arising from current NASA plans is the lack of opportunity to press on with important work in microgravity science and technology. Materials research in space is a new endeavour now being actively pursued by the Soviet Union and its partners. Spacelabs that could have helped the United States and its international partners bridge the gap to space station are now greatly restricted at a time when space station utilization is drifting later and later. Even the concept of mantended pressurized modules, which could conceivably be provided by private industry, seems to be in disfavour. In parallel with the problems facing materials science, I also note that with the current space station plan, the study of long-duration effects of space flight on humans will be seriously delayed, and this must certainly have a negative impact on the speed at which we can even seriously consider manned planetary exploration at the turn of the century.

Based on the foregoing, it is apparent that serious thought should be given to altering present space transportation and space station plans to suit the needs of space users. Alternatives offered by new vehicles such as the so-called Heavy Launch Vehicle or new types of supporting space facilities need to be considered. Ideas that call for an initial scaled-down space station which can service science users substantially earlier than is now planned must be given close attention.

The answer to your question of "Who wants the US space station?" is that science users want a space station but not necessarily the space station that has been put forward in recent months. The traditional areas of space science and the new fields related to space microgravity are not well served by current plans for a space station which arrives too late and is based on a space transportation system which is unable comfortably to meet the needs of its users. To arrive at the right space sta- tion, NASA must consider the serious plight facing its broadly based science disciplines and technology developers and come up with a more versatile plan which better satisfies user needs.

STAR Laboratory,

Peter M. Banks

Department of Electrical Engineering/

$S E L$,

Stanford University,

Stanford, California 94305, USA

\section{UK's bad example}

SIR-As a scientist visiting Britain to improve my knowledge and further the international exchange of ideas, I had not previously realized how political pressures are undermining the science-base of the country. I wanted particularly to come to the Freshwater Biological Association (FBA), because it is one of the most respected of the world's environmental institutes.

I am concerned and astonished about what is happening here. A third of the staff are to lose their jobs. To accommodate the economic cut-backs by the government, important areas of science will be eliminated, including mycology, palaeolimnology and sedimentology.

Having experienced the consequences of similar policies in my own country Brazil, where they were enacted for ideological rather than economic reasons and seen how bad it is for the progress of civil science, I am astonished and disappointed that the basic sciences can be so disregarded in a developed country.

The run-down of Brazilian science caused several of our best scientists to leave the country so that they could continue their research programmmes abroad. Some scientific areas almost completely disappeared and, decades later, some fields have not recovered. Now, in more enlightened times, we are rebuilding our institutes and universities, but only slowly, with great difficulty and at a very high cost.

This should not be allowed to happen in Britain. Other countries will take a dim view of its imposed decline. They will think that Britain has lost faith in its own abilities, and the reneging on scientific responsibility will be a poor example for the developing nations.

Economic problems will not be solved by dismissing scientists who have spent many years in training and gaining the experience to undertake their exacting work. The cost in lost morale cannot be counted.

\section{F. A. R. BARBOSA (Federal University of Minas Gerais, Brazil)}

Freshwater Biological Association,

The Ferry House,

Far Sawrey,

Ambleside, Cumbria LA22 OLP, UK 